\title{
Integrated risk assessment to natural hazards: case study - Motozintla, Chiapas, Mexico
}

\author{
D. A. Novelo-Casanova ${ }^{1}$, O. Oropeza ${ }^{2}$, E. Mansilla ${ }^{1}$, \\ J. L. Macías ${ }^{1}$, I. Alcántara ${ }^{2}$, F. J. Cantarero ${ }^{2}$, M. Figueroa ${ }^{2}$, \\ F. Rodríguez-Van Gort ${ }^{1} \&$ J. M. Sánchez-Núñez ${ }^{1}$ \\ ${ }^{1}$ Instituto de Geofisica, Universidad Nacional Autónoma de México, \\ Ciudad Universitaria, Delegación Coyoacán, C.P., México \\ ${ }^{2}$ Instituto de Geografia, Universidad Nacional Autónoma de México, \\ Ciudad Universitaria, Delegación Coyoacán, C.P., México
}

\begin{abstract}
In this work we assess the risk to natural hazards in the community of Motozintla located in southern Mexico in the state of Chiapas $\left(15.37^{\circ} \mathrm{N}, 92.25^{\circ} \mathrm{W}\right)$ with a population of more than 20,000 people. Due to its geographical and geological location, this community is continuously exposed to the impact of many different natural hazards (earthquakes, landslides, volcanic eruptions, and floods). To determine the level of risk to natural hazards in the community, we developed integrated analysis of seismic microzonation, landslide and flood susceptibility as well as volcanic impact using standard methodologies. Vulnerability was quantified from interviews of local families considering structural and socioeconomic variables. The families surveyed were randomly selected considering a sample statistically significant. All results were spatially analyzed using a Geographical Information System (GIS). Our results indicate that the community of Motozintla is highly exposed to floods, landslides and earthquakes and to a lesser extent to the impact of volcanic eruptions. The locality has a high level of structural and socio-economic vulnerability to the main identified hazards (floods and landslides). Another major observation is that the community organization for disaster prevention is practically nonexistent. These natural and social conditions indicate that the community of Motozintla has a very high level
\end{abstract}


of risk to natural hazards. This research will support local decision makers in the development of an integrated comprehensive natural hazards mitigation and prevention program.

Keywords: risk assessment, natural hazards, social vulnerability, Chiapas, Mexico.

\section{Introduction}

An integrated risk assessment includes the analysis of all components of individual constituents of risk such as baseline study, hazard identification and categorization, hazard exposure, and vulnerability. Risk is the probability of a loss, and this loss depends on two elements: hazard, and vulnerability [1]. Vulnerability is a pre-existing condition that affects a society's ability to prepare for and recover from a disruptive event. Thus, risk is the estimated impact that a hazard event would have on people, services, facilities, structures and assets in a determined community.

Disasters arising from hazards of natural origin are only partially determined by the physical event itself. Reducing disaster risk requires the assessment of the level of the hazard and the various types of vulnerabilities (economical, social, environmental, etc.) of the affected society. Hazards are often grouped into three main categories, according to their causes: natural (earthquakes, hurricanes, etc.), technological (explosions, release of toxic material, etc.) and anthropogenic (terrorist activity, crowd-related, etc.) [2]. However, hazards may have interrelated causes and the allocation of a hazard to one class is often difficult.

Vulnerability is a function of the level of sensitivity or susceptibility of a system (community, household, building, infrastructure, nation, etc.) to be damaged. Rashed and Weeks [3] pointed out that vulnerability is independent from any particular magnitude of a specific natural event and depends only on the social context in which it occurs. Thus, vulnerability cannot be assessed in absolute terms. The performance of a determined community should be assessed with reference to specific spatial and temporal scales.

In this work, we assess the risk to natural hazards (earthquakes, landslides, volcanic eruptions and floods) considering the social and economic vulnerability of the community of Motozintla located in Chiapas, southern Mexico $\left(15.37^{\circ} \mathrm{N}\right.$, $\left.92.25^{\circ} \mathrm{W}\right)$ (Fig. 1).

\section{Natural hazards in Motozintla}

Motozintla is frequently impacted by natural events. Recently, this community faced two disasters due to flooding and landslides. The first of these disasters occurred during hurricane Earl in 1998. The population was impacted by the occurrence of heavy rains up to $350 \mathrm{~mm}$ in 48 hours. This phenomenon caused 200 deaths and about 8,000 people were directly affected [4]. The second disaster took place during hurricane Stan in October 2005, affecting about 66\% of the municipality and generating damages to the state of Chiapas by approximately 640 million dollars [5]. In addition, other hydro-meteorological 
events in 1985, 1988, 1997, 2000, and 2006 also caused damage to the agriculture sector as well as the local rural infrastructure.

The estate of Chiapas is one of those with great seismicity in Mexico. At the beginning of last century, three large earthquakes of magnitude greater than 7 occurred in this region $(1902,1903)$ causing great damage to the local community. Recent earthquakes took place in $1970(\mathrm{M}=7.3)$, and $1993(\mathrm{M}=7.2)$ with epicenters in southern Chiapas [6]. Landslides occur regularly in Motozintla. During the 1998 hurricane event, more than 300 people died in the communities of Motozintla, Jaltenango de la Paz, and Valdivia in the state of Chiapas as a consequence of this phenomenon. In 2005, hurricane Stan generated several landslides killing 10 people in Motozintla [5].

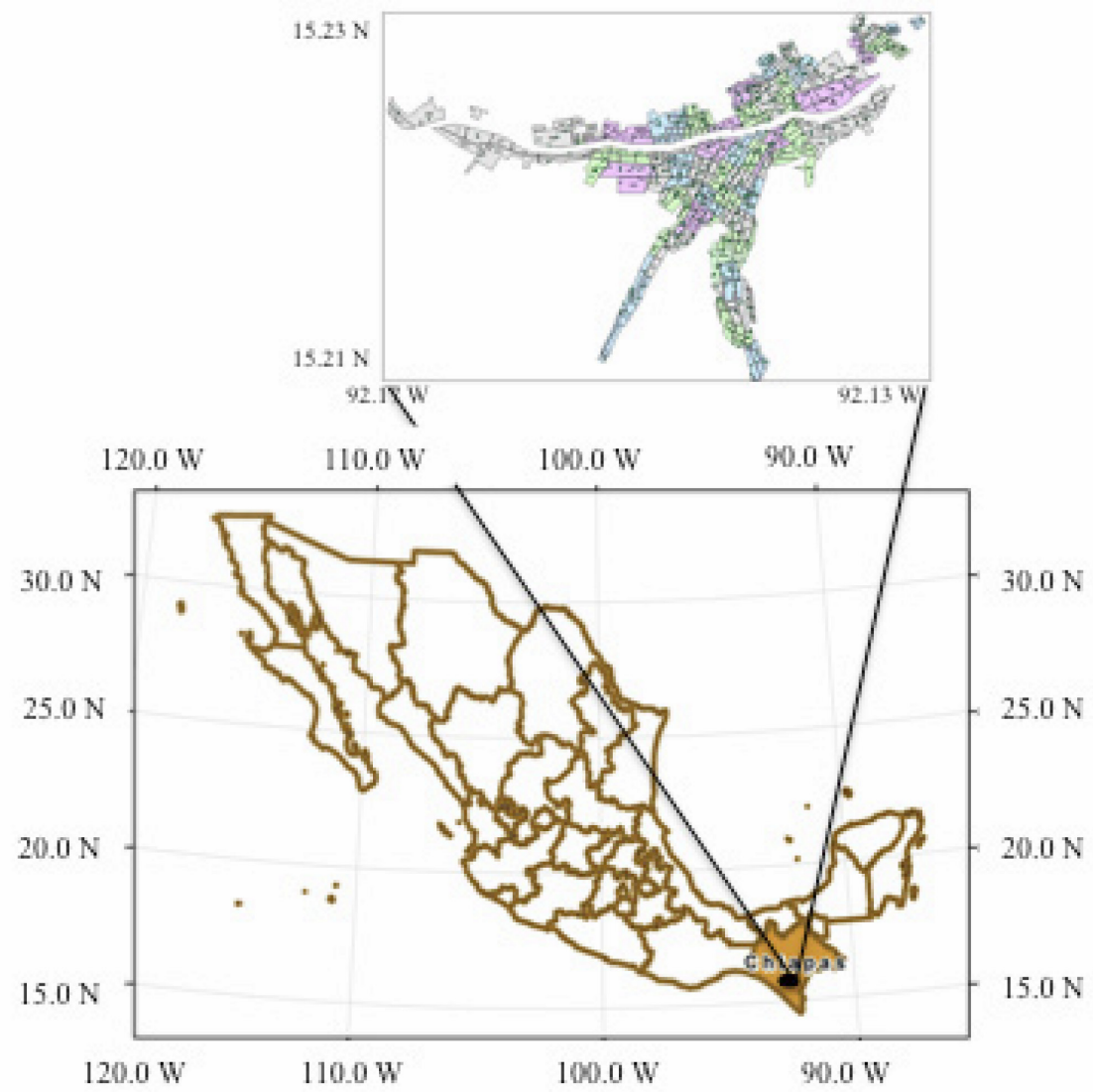

Figure 1: $\quad$ Location of the area of study.

Although the city of Motozintla is potentially exposed to the effect of eruptions of Chichon and Tacana volcanoes, the historic geology of this region indicates that large volcanic eruptions have impacted in the past to pre-hispanic human settlements around Motozintla by only small amounts of ash-fall [7]. 
Under these conditions, we consider that volcanic hazard is practically nonexistent and that no further evaluation is needed in this respect.

\section{Methodology}

To determine the level of risk of the community of Motozintla to natural hazards, we developed integrated studies and analysis of seismic microzonation, landslide and flood susceptibility using standard methodologies. We estimated the structural and socio-economic vulnerabilities using the variables indicated in Table 1. Five levels of vulnerability were considered: very high, high, moderate, low and very low. To have a 95\% confidence level in our survey, we considered a sample size of the community statistically significant. Once the number of families living in Motozintla was determined, we selected the families to be interviewed using the simple random sampling technique with replacement. With these procedures, each family was chosen randomly and entirely by chance with the same probability of being chosen at any stage during the sampling process. Considering that the number of households in Motozintla is 5,000 the minimum survey sample size is 386 . However, we surveyed a total of 444 families. The interviewed persons were residents aged 15 years and over that have responsibilities in household maintenance.

Three field works were carried out (October and November 2009; October 2010) to collect data for vulnerability analysis. The different estimated levels of vulnerability were spatially located using a Geographical Information System and the Inverse Distance Weighted (IDW) process.

\section{Results}

To facilitate our analysis, our results are presented in spatial maps showing the areas of different levels of exposure and/or risk to the analyzed hazards. These maps are intended to be useful tools for emergency managers and policy developers and to increase the overall awareness of decision makers for the implementation of disaster prevention and mitigation plans in Motozintla. It is important to underline that this study presents a first evaluation of the main natural hazards that may affect Motozintla. A full hazard analysis of this community should include a complete and quantitative hazards assessment modeling. However, our results constitute the basis of future mitigation risk projects in this town.

\subsection{Earthquake hazards}

Using the method of Nakamura [8], we identified three different spatial seismic zones in Motozintla: Zone I, Zone II and Zone III with low, high and very high seismic amplification areas, respectively (Fig. 2). This site conditions indicate that Motozintla can be highly impacted by a large earthquake in the future. The soil response to seismic waves is very high near to the main river bed where most of the houses were identified with high structural vulnerability (see below). 
Table 1: $\quad$ Variables and levels of vulnerability.

\begin{tabular}{|c|c|c|}
\hline Vulnerability & Variables & $\begin{array}{l}\text { Level of Vulnerability } \\
\text { (number of variables that } \\
\text { increase vulnerability) }\end{array}$ \\
\hline Structural & $\begin{array}{l}\text { House with: } \\
\text { 1. Laminated roof } \\
\text { 2. Block walls } \\
\text { 3. One floor } \\
\text { 4. With a maximum of two } \\
\text { rooms }\end{array}$ & $\begin{array}{l}\text { Low: One } \\
\text { Moderate: Two } \\
\text { High: Three } \\
\text { Very high: Four }\end{array}$ \\
\hline $\begin{array}{l}\text { Socio- } \\
\text { economic }\end{array}$ & $\begin{array}{l}\text { Household living conditions: } \\
\text { 1. More than five family } \\
\text { members living in the house } \\
\text { 2. Family member over } 70 \\
\text { or/and under } 5 \text { years old } \\
\text { 3. Family member with } \\
\text { disability } \\
\text { 4. Existing illiterate member } \\
\text { 5. Lack of institutional medical } \\
\text { service } \\
\text { 6. No television and/or radio } \\
\text { 7. No telephone or mobile } \\
\text { phone } \\
\text { 8. Income less than the } \\
\text { minimum government wage } \\
\text { 9. Lack of capacity for savings } \\
\text { Lack of basic services }\end{array}$ & $\begin{array}{l}\text { Very low: One } \\
\text { Low: Two-Three } \\
\text { Moderate: Four-Five } \\
\text { High: Six-Seven } \\
\text { Very High: Eight-Nine }\end{array}$ \\
\hline & $\begin{array}{l}\text { 1. Water } \\
\text { 2. Drainage } \\
\text { 3. Electricity } \\
\text { Lack of response plans }\end{array}$ & $\begin{array}{l}\text { Low: One } \\
\text { Moderate: Two } \\
\text { High: Three }\end{array}$ \\
\hline & $\begin{array}{l}\text { 1. Governmental } \\
\text { 2. Neighborhood }\end{array}$ & $\begin{array}{l}\text { Moderate: One } \\
\text { High: Two }\end{array}$ \\
\hline Global & $\begin{array}{l}\text { Any structural and/or socio- } \\
\text { economic variable }\end{array}$ & $\begin{array}{l}\text { Very low: One-Four } \\
\text { Low: Five-Eight } \\
\text { Moderate: Nine-Twelve } \\
\text { High: Thirteen-Sixteen } \\
\text { Very high: Seventeen- } \\
\text { Eighteen }\end{array}$ \\
\hline
\end{tabular}

Motozintla is affected by earthquakes from two seismic sources: the PolochicMotagua Fault and the Mexican Seismic Trench [9]. Although with the present knowledge, the return period of these seismic sources cannot be determined, the 
occurrence of a large earthquake along the Polochic-Motagua fault may cause a major impact to the community. The Motagua-Polochic fault system is particularly active as evidenced by the great 1976 earthquake (Ms=7.5) [10]. This fault also ruptured in previous large earthquakes during last century: 1945 $(\mathrm{Ms}=5.7) ; 1980(\mathrm{Ms}=6.4)$ [11]. Thus, we consider that earthquakes are one of the main hazards to which Motozintla is in high risk. However, our study demonstrates that some variations of an earthquake impact may exist due to the different soil conditions (Fig. 2).

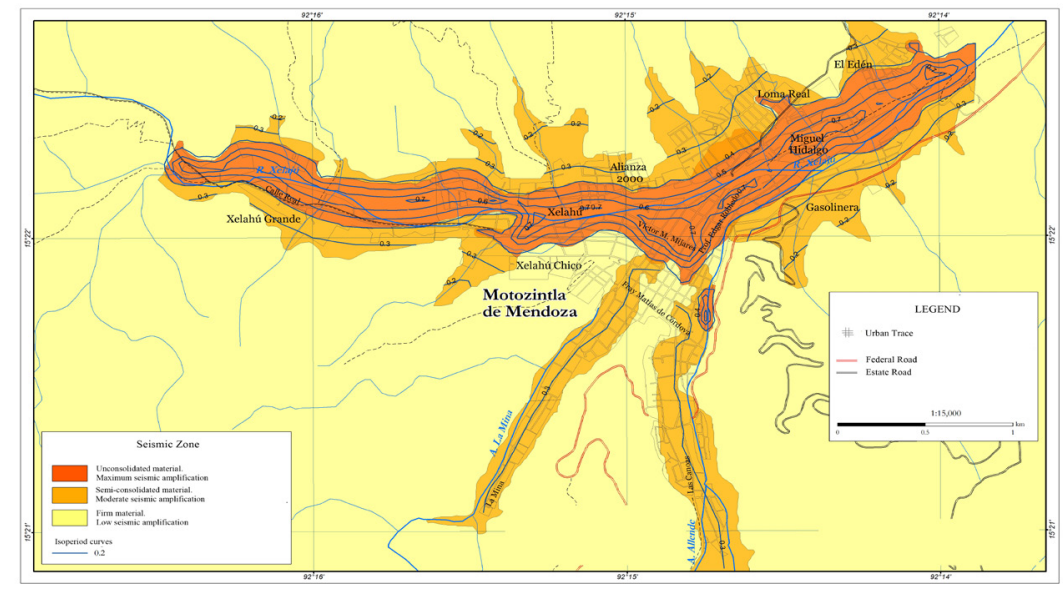

Figure 2: Seismic amplification areas in Motozintla. Zone 1: Low amplification zone; Zone II. High seismic amplification area (four times larger than in Zone I); Zone III. Very high seismic amplification area (five times larger than in Zone I).

\subsection{Mass movements hazards}

We identified 88 zones that were subject to large mass movement processes during the past $25 \mathrm{ky}$ represented by debris avalanches, rock falls, slides and debris flows (Fig. 3). These 88 areas are a natural potential hazard for the Motozintla basin. Although landslides and debris flows are dangerous phenomena that may directly impact the city of Motozintla, those events related to road construction and opencast activities may also have a high social impact in the area. Future mass movement processes may happen mainly in the NW part of the basin where highly altered rocks of the Chiapas massif and Todos Santos Formation are exposed. The 1998 and 2005 hydro-meteorological events provoked hundreds of landslides in the Motozintla basin from the upper parts of the basin, transporting loose debris downhill loading the rivers and eventually flooding the town of Motozintla and other small communities.

We consider Motozintla with a high risk to mass movement hazards (Fig. 3) because of the following identified reasons: 1) The geo-morphological 
characteristics of the local topography; 2) The local high exposure to hydrometeorological events such as hurricanes and heavy precipitations that cause frequent mass movements; and 3) Their large direct social impact.

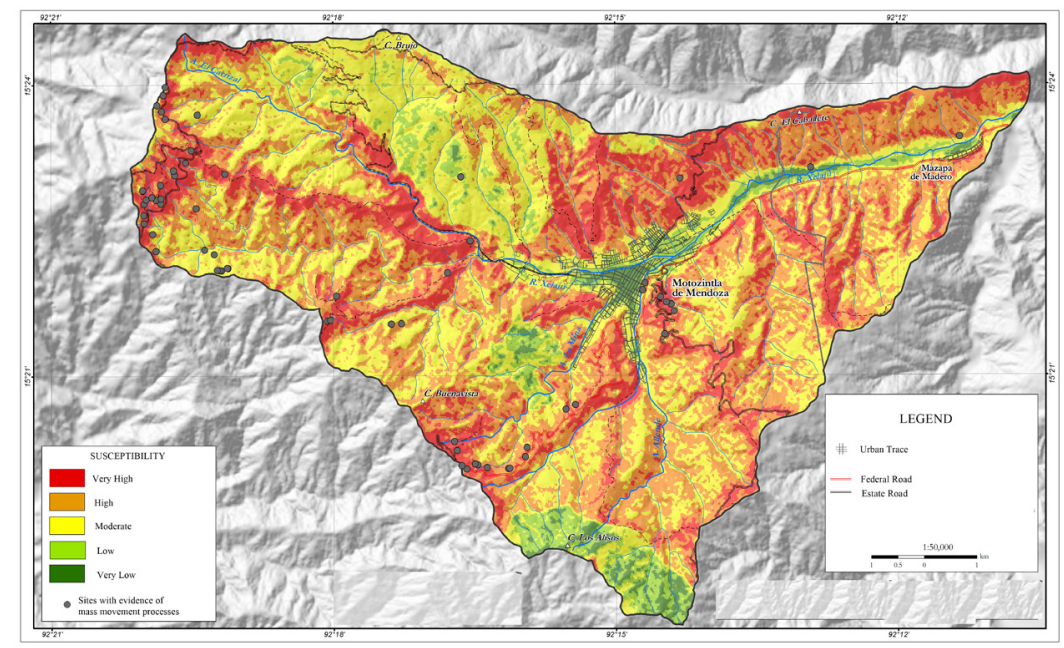

Figure 3: Mass movements susceptibility.

\subsection{Flood hazards}

In September 1998, the rainfall of the tropical storm "Earl" totaled 175 and 130 $\mathrm{mm}$ on September 8 and 9, respectively, duplicating in two days the average monthly precipitation in the region. Most sections of Motozintla city were inundated during these hydro-meteorological events. Communication of Motozintla with the rest of the Chiapas state was interrupted for about a month as well as the supply of potable water, food, electricity, and fuel [12]. Flooding in Motozintla has been the cause of death and of much property damage. The Xelaju River has been the pathway of large floods during the last 6000 years. At least two historic floods have occurred during the last 100 years [12].

Frequency analysis of the historical record of daily rainfall in the Motozintla area suggests that events like that of September, 1998, have a recurrence interval of about 25 years [12]. In this work three possible flood scenarios were considered with period of recurrence of 5, 10 and 20 years for precipitations of 30, 99, and $528 \mathrm{~mm} / \mathrm{hr}$, respectively (Fig. 4). The areas identified with greater exposure to flood hazard are those near the Xelaju river. Clearly, property location and conditions is critical during floods.

Based on our discussion above and because of the frequent high rates of average and daily rainfall, we consider flooding from rainfall as the most important hazard in Motozintla. 


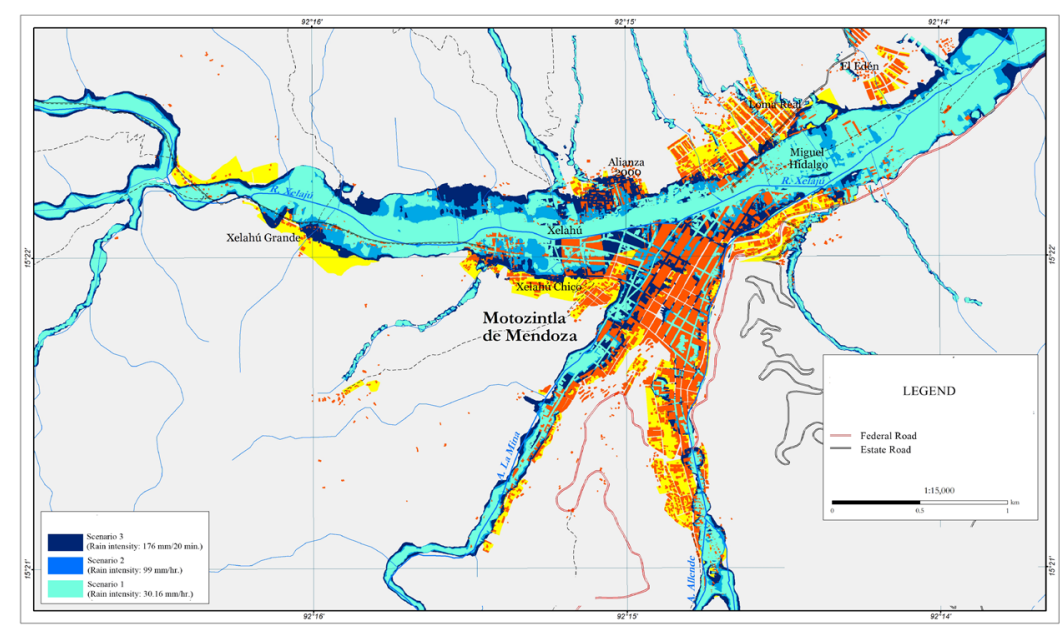

Figure 4: Flood hazard scenarios for the studied region.

\subsection{Global vulnerability and flood risk}

The measured structural vulnerability varies from medium to low, especially in the central part of Motozintla. Towards the northern side of the town, the structural vulnerability conditions are high because about $60 \%$ of the houses are built with low cost materials (adobe) (map not shown here).

The socio-economic vulnerability of the city of Motozintla was measured between moderate and high. Approximately $72 \%$ of the local families have a daily expense that varies from 3 to 11 USA dollars. About $36 \%$ of the population does not have any type of social security services and from this group, only $7 \%$ are entitled to complete services that include hospitalization and surgical procedures. Approximately $66 \%$ of the population of Motozintla stated that they de not know any government or municipal emergency plan to respond in case of emergencies. Also, they indicated the lack of a neighborhood action plan to attend disaster situations.

We call "global vulnerability" to the result of combining structural and socioeconomic vulnerabilities. Global vulnerability is considered as those elements that make the population susceptible to suffer damages in their physical integrity, belongings and environment due to the occurrence of a disastrous event. A high percentage $(60 \%)$ of the territory of Motozintla was identified with high global vulnerability while a $30 \%$ have moderate vulnerability and $10 \%$ of the territory has very high vulnerability (maps not shown here).

Due to the fact that floods are one of the major natural hazards in Motozintla, Fig. 5 displays the risk of the population of Motozintla considering the level of the identified flood hazards and the estimated global vulnerability. Our results indicate that most of the Motozintla community (about 95\%) has a high level of 
global vulnerability to flood hazards. As a consequence, Motozintla is in high risk to floods. This result is mainly associated to the local social conditions and the poor structural housing constructions.

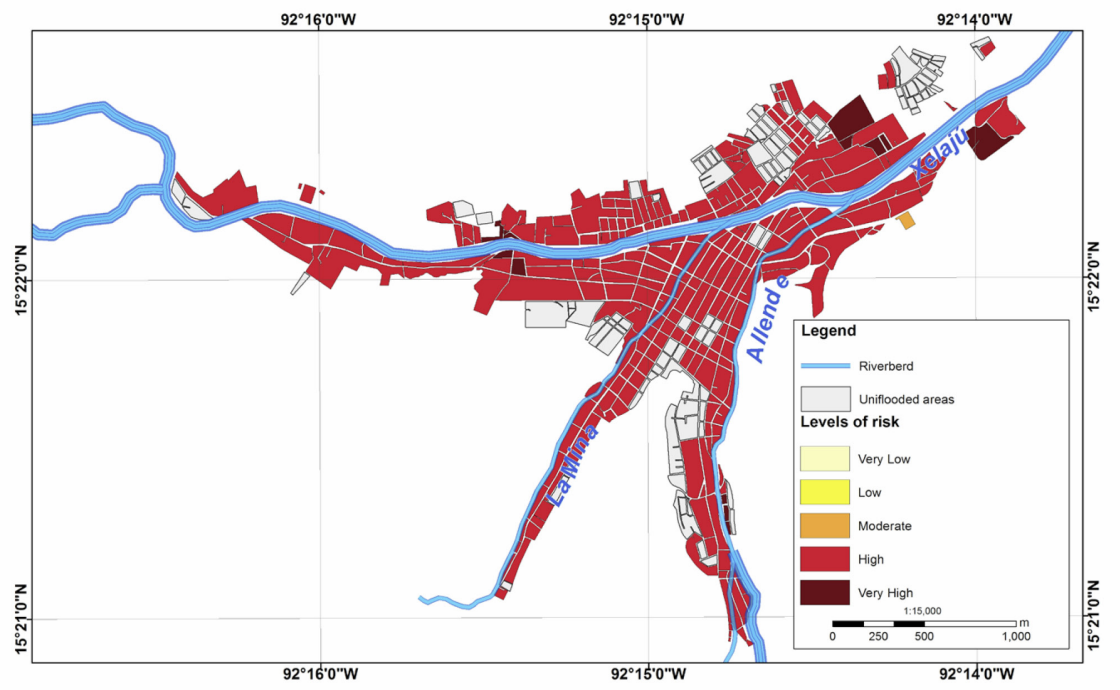

Figure 5: Spatial distribution of global vulnerability and flood hazard.

\section{Discussion}

Our results indicate that the community of Motozintla is highly exposed to floods, landslides and earthquakes and to a lesser extent to the impact of volcanic eruptions. The local impact of an earthquake will vary due to the different soil conditions. Mass movements are one of the main hazards in the region due to the geo-morphological and topographical characteristics as well as the high rate of hydro-meteorological events. Because of the high rates of annual rainfall, flooding is the most important hazard in Motozintla. The risk to all these natural hazards is increased by the high levels of the global vulnerability measured.

The structural vulnerability is greater towards the north and northeastern zones of Motozintla. In general, the structural vulnerability varies from moderate to low, especially in the central part of Motozintla. We determined that the local structural vulnerability has higher influence in the increase of risk than the lack of public basic services, which although unfavorable for the population, it is not a factor for preserving life or housing. Another interesting result is that the lack of preparation of the community to face a disaster generates a higher risk level than the other analyzed socio-economic conditions.

Global vulnerability indicates that the area with the highest flood risk is located in the margins of the Xelajú River. This area is where the rivers Xelajú, Allende and La Mina meet and the river flow increases (Fig. 5). Another social 
factor that increases vulnerability is the fact that approximately $66 \%$ of the population reported that does not know any existing Civil Protection Plan.

It is important to understand that disasters arising from hazards of natural origin are only partially determined by the physical event itself. Thus, reducing disaster risk requires the assessment of the level of the hazard and the various types of vulnerabilities (economical, social, environmental, etc.) of the affected society. In this work, we determined the levels of the natural hazards that the city of Motozintla is exposed as well as its structural, socio-economic and global vulnerabilities and our integrated analysis represent an important step for the development a of an integrated comprehensive natural hazards mitigation and prevention program.

\section{Conclusions}

The community of Motozintla is highly exposed to floods, landslides and earthquakes. The locality also has a high level of global vulnerability. These natural and social conditions indicate that the community of Motozintla has a very high level of risk to natural hazards (mainly floods, landslides and earthquakes). This research will support the overall awareness of decision makers in Mexico, and particularly from the state of Chiapas, for the development of an integrated comprehensive natural hazards mitigation and prevention program in this region.

\section{Acknowledgements}

The authors are grateful to an anonymous reviewer for his thoughtful review of this work and providing helpful comments. Our appreciation to the local authorities of the government of Motozintla that made this study possible and who kindly provided their expertise, time and data. This research was supported from grants of the Mexican National Council of Science and Technology (CONACYT; Project No. 56624) and the Program to Support Research Projects and Technology Innovation of the National Autonomous University of Mexico (UNAM; PAPIIT Project No. IN116208).

\section{References}

[1] Cutter, S.L., Boruff, B. Jm. \& Shirley, W.L., Social Vulnerability to Environmental Hazards. Social Science Quarterly. 84(2), pp. 242-261, 2003.

[2] Schneiderbauer, S, \& Ehrlich, D. Social levels and hazard (in) dependence in determining vulnerability. Measuring Vulnerability to Natural Hazards Towards Disaster Resilient Societies, ed. J. Birkmann, United University Press, pp. 78-102, 2006. 
[3] Rashed, T. \& Weeks, J., Assessing vulnerability to earthquake hazards through spatial multicriteria analysis of urban areas. Int. J. Geograp. Info. Sc. 17, pp. 547-576, 2003.

[4] Economic Commission for Latin America and the Caribbean (ECLAC) Web Site, Mexico DF, http://www.eclac.org/publicaciones/xml/0/27710 /L751-9.pdf.

[5] Mexican National Center for Disaster Prevention (CENAPRED) \& Economic Commission for Latina American and the Caribbean (ECLAC) Web Site, Mexico DF, http://www.eclac.org/publicaciones/xml/0/27710 /L751-3.pdf.

[6] Mexican National Seismological Service (SSN) Web Site, Mexico DF, http://www.ssn.unam.mx/

[7] Macías, J.L., Arce J.L., García-Palomo A., Mora J.C., Layer P. \& Espíndola J.M., Late- Pleistocene flank collapse triggered by dome growth at Tacaná volcano, México-Guatemala, and its relationship to the regional stress regime. Bull. Volcanol., 72, pp. 33-53, 2010.

[8] Nakamura, Y., A Method for Dynamic Characteristics Estimation of Subsurface using Microtremor on the Ground Surface. Quarterly Report of Railway Technical Research Institute, 30 (1), pp. 25-33, 1989.

[9] Guzman-Speziale, M. \& Meneses-Rocha J., The North America-Caribbean plate boundary west of the Motagua-Polochic fault system: a fault jog in Southeastern Mexico. J. South American Earth Sciences, 13, pp. 459-468, 2000.

[10] Kanamori, H. \& Stewart G., Seismological aspects of the Guatemala earthquake of February 4, 1976. J. Geophys. Res., 83, pp. 3427-3434, 1978.

[11] White, R.A. \& Harlow D.H., Destructive upper-crustal earthquakes of Central America since 1900. Bull. Seismol. Soc. Am., 83, pp. 1115-1142, 1993.

[12] Caballero G.A., Macías J.L., García-Palomo A., Saucedo G.R., Borselli L., Sarocchi D. \& Sánchez-Nuñez J.M., The September 8-9 rain-triggered flows at Motozintla, Chiapas, México. Nat. Haz., 39, pp. 103-126, 2006. 